Article

\title{
Trajectory Optimization of Industrial Robot Arms Using a Newly Elaborated "Whip-Lashing" Method
}

\author{
Rabab Benotsmane ${ }^{1}$, László Dudás ${ }^{1}$ and György Kovács ${ }^{2, *}$ \\ 1 Department of Information Technology, University of Miskolc, 3515 Miskolc, Hungary; \\ iitrabab@uni-miskolc.hu (R.B.); iitdl@uni-miskolc.hu (L.D.) \\ 2 Institute of Logistics, University of Miskolc, 3515 Miskolc, Hungary \\ * Correspondence: altkovac@uni-miskolc.hu
}

Received: 12 November 2020; Accepted: 1 December 2020; Published: 3 December 2020 updates

\begin{abstract}
The application of the Industry 4.0's elements—e.g., industrial robots—has a key role in the efficiency improvement of manufacturing companies. In order to reduce cycle times and increase productivity, the trajectory optimization of robot arms is essential. The purpose of the study is the elaboration of a new "whip-lashing" method, which, based on the motion of a robot arm, is similar to the motion of a whip. It results in achieving the optimized trajectory of the robot arms in order to increase velocity of the robot arm's parts, thereby minimizing motion cycle times and to utilize the torque of the joints more effectively. The efficiency of the method was confirmed by a case study, which is relating to the trajectory planning of a five-degree-of-freedom RV-2AJ manipulator arm using SolidWorks and MATLAB software applications. The robot was modelled and two trajectories were created: the original path and path investigate the effects of using the whip-lashing induced robot motion. The application of the method's algorithm resulted in a cycle time saving of $33 \%$ compared to the original path of RV-2AJ robot arm. The main added value of the study is the elaboration and implementation of the newly elaborated "whip-lashing" method which results in minimization of torque consumed; furthermore, there was a reduction of cycle times of manipulator arms' motion, thus increasing the productivity significantly. The efficiency of the new "whip-lashing" method was confirmed by a simulation case study.
\end{abstract}

Keywords: manipulator arm; trajectory optimization; "whip-lashing" method; reduction of cycle time; trajectory planning; SolidWorks and MATLAB software applications

\section{Introduction}

Nowadays, the modern industry in all sectors is facing a new revolution known as Industry $4.0[1,2]$, where many challenges and requirements are taken into consideration with the aim of building smart factories that combine flexibility and ability concepts [3,4] by developing a new paradigm based on the latest technologies, where automation and network systems present the efficient keys for realizing the new industrial revolution [5].

Recently, industrial robotics has become an important solution used in different sectors due to the advantages guaranteed by industrial robots [6] as manipulator arms and parallel robots represented with higher precision and higher productivity. This optimizes the lead time of the production process [7].

Especially with technological developments, the manipulator arm, for example, presents the most often used tool in the production sector [8], where it can cooperate with its environment and work safety $[9,10]$. In addition to the ability to pick huge products and control itself in a flexible and smart way, the physical structure of the manipulator arm regroups two essential parts [11]. These parts are the serial links articulated as an arm and the end-effector, which can be reconfigurable according to the 
task $[12,13]$. The motion planning of a manipulator arm is always based on the degree of freedom characterized by the joints placed in each link, where the number of the degree of freedom limits the workspace and defines the redundancy of the robot. The control of manipulator robots can be studied in two directions, depending on the requirements needed to achieve it [14]: (1) task execution, where the process is based on pick and place, welding, and painting; (2) path planning execution, where the process is based on the trajectory of the end effector, depending on each joint connected to the link of the robot arm.

In the area of robotics, the trajectory planning of manipulator arms represents an essential field for focus. The execution of a robot arm's defined task optimizes its trajectory, which can guarantee many benefits such as a reduced cycle time and energy consumption, as well as increased productivity. Basically, the main objective in the trajectory planning field is to compute the desired points that represent the reference input data for the controller of a robot using mathematical techniques $[15,16]$. The motion executed from the reference inputs always represents two categories known as forward and inverse kinematics: (1) in free space based on the joint angles, where the motion is limited by the structure constraints, i.e., velocity, torque, and workspace limits; or (2) in task space based on the position and the orientation of the end-effector, where it depends on precision and avoiding obstacles [17]. The approaches generally used are polynomial interpolation function, the bang-bang law, the trapezoid law, etc. [18].

Over the years, researchers studied this field deeply by proposing many methods and solutions to solve trajectory problems for industrial robots [19-22]. The definition of the optimality concept is divided in many directions. Some scientists focus on a time-optimal trajectory to increase productivity [23,24], while others work on the smoothness of trajectories [25,26], taking into account reducing cycle time by implementing fast trajectories combined with optimal jerk values in order to reduce the excitation of the resonant frequencies and limit the vibrations of the mechanical system [27-29]. From the literature, a basic approach is known for generating a trajectory using splines [30,31], where the virtual points are required to ensure the continuity of the trajectory from the starting point to the endpoint. The development of this approach motivated the authors of this study to apply an improved technique in the aspect of motion optimality using B-spline interpolation, based on the calculation of inverse of Jacobian matrix.

Regarding time optimality, an approach was proposed for a hyper-redundant robot taking into account the obstacles located in a 3D workspace [32,33]. It aims to minimize the cycle time during the execution of required tasks, regarding trajectory optimization for robots in terms of energy consumption and minimizing joint torque. Other researchers described a new scheme to determine the trajectory of a redundant robot arm with the purpose of minimizing the total energy consumption [34]. In order to optimize both the energy consumption and the time required for executing a trajectory, many researchers have elaborated new methods based on a fuzzy logic algorithm, a genetic algorithm, or an ant colony algorithm $[34,35]$. By using a genetic algorithm, a contribution was proposed to optimize the torque applied at the joints of the robot [36,37]. We can also cite the second contribution for the same target, which uses a unified quadratic-programming-based dynamic system [38], as well as the role of neural networks for the optimized dynamics of redundant robots [39]. Most of the literature in motion planning features deals with point-to-point applications in free space without any obstacles, where the starting and ending points of the end-effector are predefined.

The main purpose of this literature analysis was to guarantee a deeper understanding of the path planning field so that researchers could find an optimal solution without any constraints. Further, time and energy consumption presents the most important factors for evaluation [40].

The purpose of this study is to elaborate upon a new "whip-lashing" method that aims to realize an optimized trajectory for the five-degree-of-freedom RV-2AJ robot arm, i.e., to generate a path for a manipulator arm without any design constraints. This newly elaborated method seeks to minimize the cycle time of the trajectory with constrained torque values applied in joints for executing smooth motions. This new method originates from the motion of a whip analogue applied for a RV-2AJ 
robot arm. First, we introduce the methodology of this newly elaborated method, identifying all the steps required using SolidWorks and MATLAB software applications. After, the main features of whip-lashing are introduced and the Section 4 presents a concrete simulation executed for both paths in order to compare the normal motion of the arm to a whip lashing motion, based on cycle time. The final section presents the results of the joints torque variation according to the cycle time calculated in the previous section in order to show the reader the effect of the whip-lashing motion on the cycle time and the torque consumption.

The main value of the research is that a manipulator arm can be treated as a whip in certain conditions, which can guarantee running an improved path that results in reduced cycle time. The proof of this novelty is presented by applying the real parameters of an RV-2AJ arm to simulation tools.

\section{Materials and Methods: Modelling the Robot Arm and the Original and Improved Trajectories}

The idea of trajectory improvement is taken from the motion of a whip. When applying a huge force at the handle, it will propagate along the whip's length, with a wave running alongside the whip transferring the energy from the handle to the tip. In order to realize this idea and check its real effect on the cycle time of robot arm motion, SolidWorks [41] and MATLAB [42] software applications were used in the dynamic motion simulations. For comparison, an "original" path with simple angle interpolation at the joints was also simulated. The two will be compared.

\subsection{Dynamic Analysis of RV-2AJ Robot Arm}

The dynamic analysis of RV-2AJ arm requires the computation of the inertia matrix for each joint. This computation is performed using SolidWorks software by drawing the robot model and applying its real geometric and mass measurements. SolidWorks offers the possibility to transform all of the robot parameters in a URDF (Unified Robotic Description Format) file; this file can be used for the simulation in MATLAB software using Robotic Toolbox [43]. Figure 1 presents the CAD model of RV-2AJ arm in SolidWorks environment and the creating of its URDF file for MATLAB software. The URDF file allows us to import the dynamic parameters of RV-2AJ arm into a MATLAB environment, where we can visualize the robot arm and calculate its forward and inverse kinematics using the Robotic Toolbox that provides the following:

- $\quad$ RigidBodyTree (RBT) object,

- Home configuration function,

- Inverse Kinematic solver.
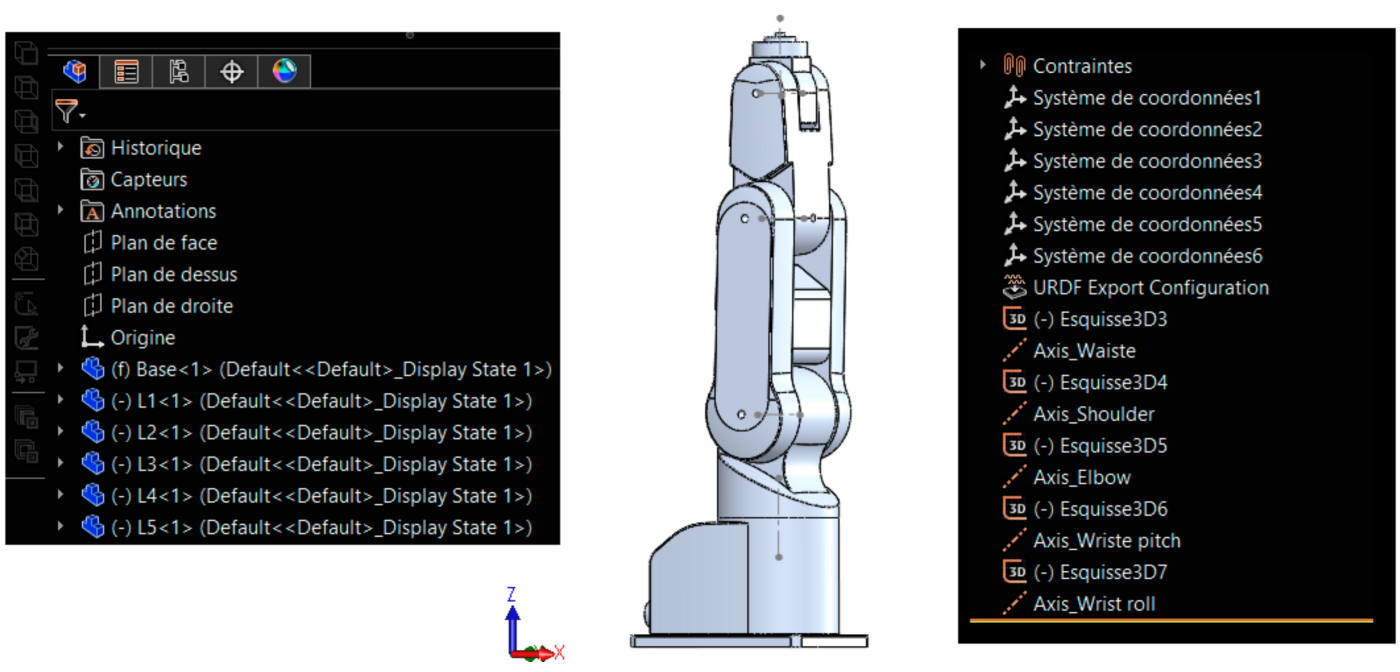

Figure 1. RV-2AJ model in SolidWorks and the created URDF (Unified Robotic Description Format) file for the CAD model of the RV-2AJ arm. 
Figure 2 visualizes the imported structure of RV-2AJ arm in the MATLAB environment and the script code used for it. The visualization of the robot arm uses the RV-2AJ.URDF definition file and the "show (robot, Qhome)" command performs the visualization, as can be followed in the MATLAB code.

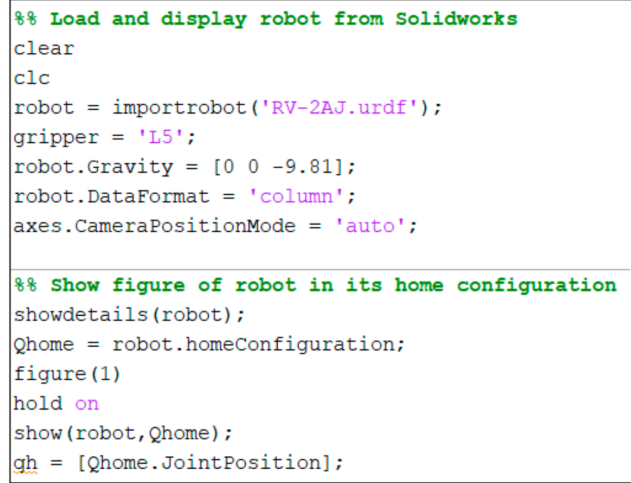

Figure 2. Visualization of RV-2AJ arm in the MATLAB environment.

For finding better or "quasi-optimal" solution and proving the effectiveness of the newly elaborated whip-lashing method, two paths were generated with the same starting and ending points but with different internal motions. During the application of the method both paths require the rotation of second-third-fourth joints, whereas the first and the fifth articulation are not used.

\subsection{The Original Path}

The original trajectory as a usual interpolated path is presented in Figure 3 as a continuous red arc starting from start point $S$ and ending in final point $E$. In this path the RV-2AJ robot arm executes its motion by computing the angle steps for each internal point dividing the start-end angle of every joint with the number of points minus one step.

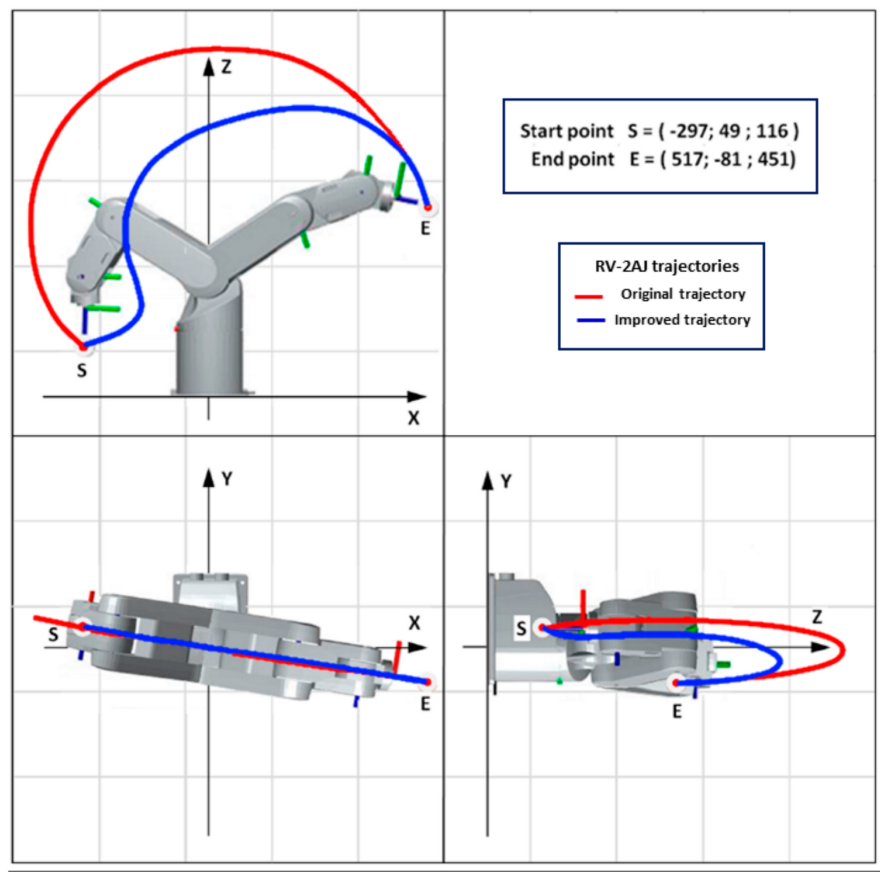

Figure 3. The trajectories of the RV-2AJ arm in three views. 


\subsection{The Improved Path}

The suggested trajectory-named "improved path" given in blue in three views (front, top, and left side views) with the robot arm in Figure 3-is based on the newly elaborated special method that imitates the natural motion of a whip. The improved path aims to decrease the cycle time for RV-2AJ arm's movement from the starting point $S$ to the final point $E$. This method is based on principle of the whip-lashing motion that determines the torques applied in closing and opening of joints of the arm, which will be discussed in the further sections.

\section{Results: Newly Elaborated “Whip-Lashing" Method}

For centuries whips have been considered instruments used to direct animals or torture slaves. Nowadays, this instrument has become an artform for some nations. In the last few years, researchers have been interested in the phenomenon executed by whips, which is characterized by the crack sound and the velocity that can reach supersonic speed [44,45]. Figure 4 presents the basic elements of a simple whip.

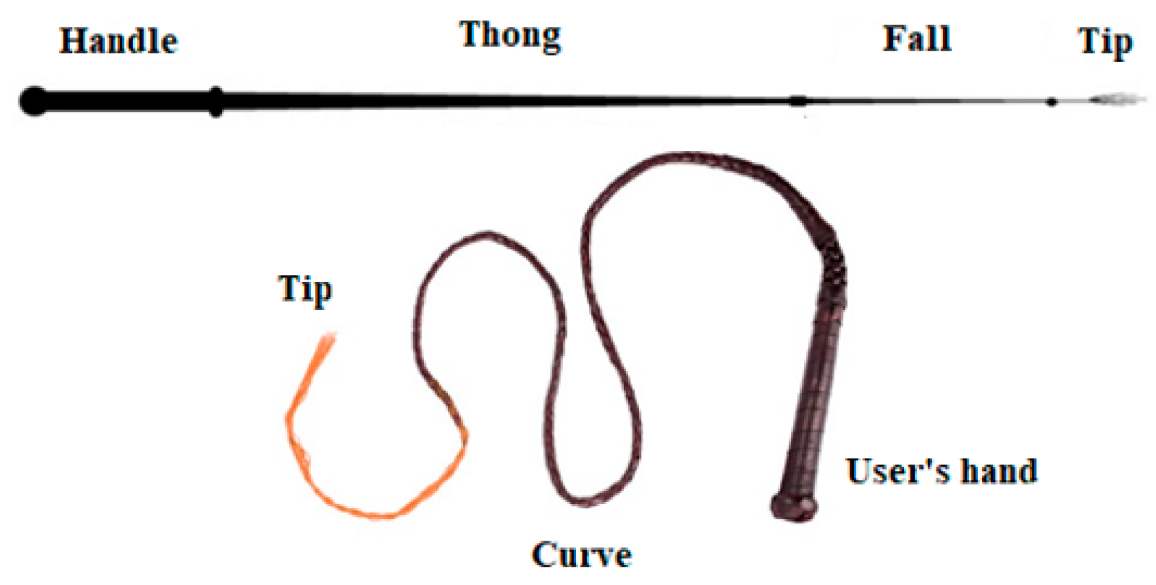

Figure 4. Basic elements of a whip.

When we give a force for a whip with the "handle" to move up to down and then stop, that produces kinetic energy. This energy will be transferred to the end of whip "tip" due to $p=m \times v$, where the mass $(m)$ decreases and the velocity $(v)$ increases.

The result of this is a sonic boom produced by a crack that is caused when some section of the whip moves faster than the speed of sound. The motion of a whip can include three types: a half wave, a full wave and a loop. Figures 5 and 6 present the transfer direction of momentum along the segments of whip and the diagrams describe the change of velocity, mass, kinetic energy and torque as a function of time. The input values used in the diagrams in Figure 6 were taken from Krehl et al. [46]. The subfigures show the following functions:

(1). The velocity diagram shows the changing of the velocity of the tip during a whip-lashing cycle.

(2). The mass diagram shows the changing of the mass of that part of the whip that has the most the kinetic energy during the whip-lashing as the wave impulse goes along the whip length.

(3). The kinetic energy diagram corresponds to the work of the whip user who moves the whip and conveys motion energy to the whip with his hand.

(4). The torque diagram shows the torque value changing in the wrist joint during the whip-lashing. 


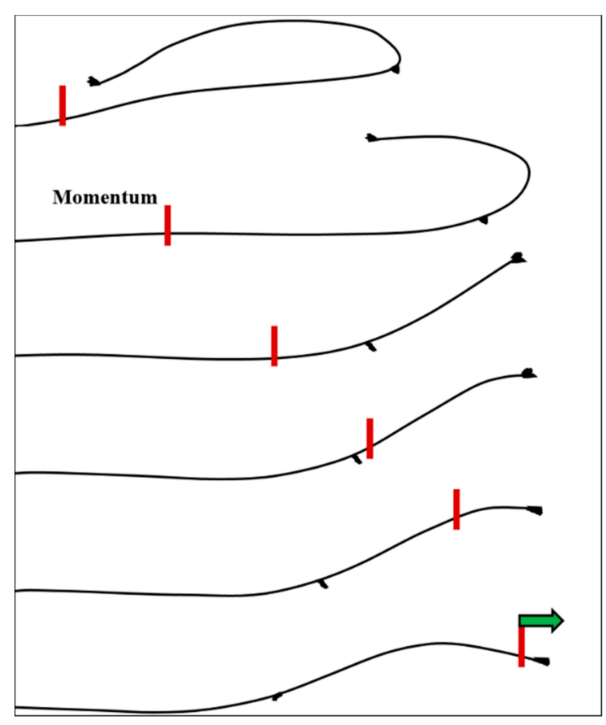

Figure 5. The motion of a whip.
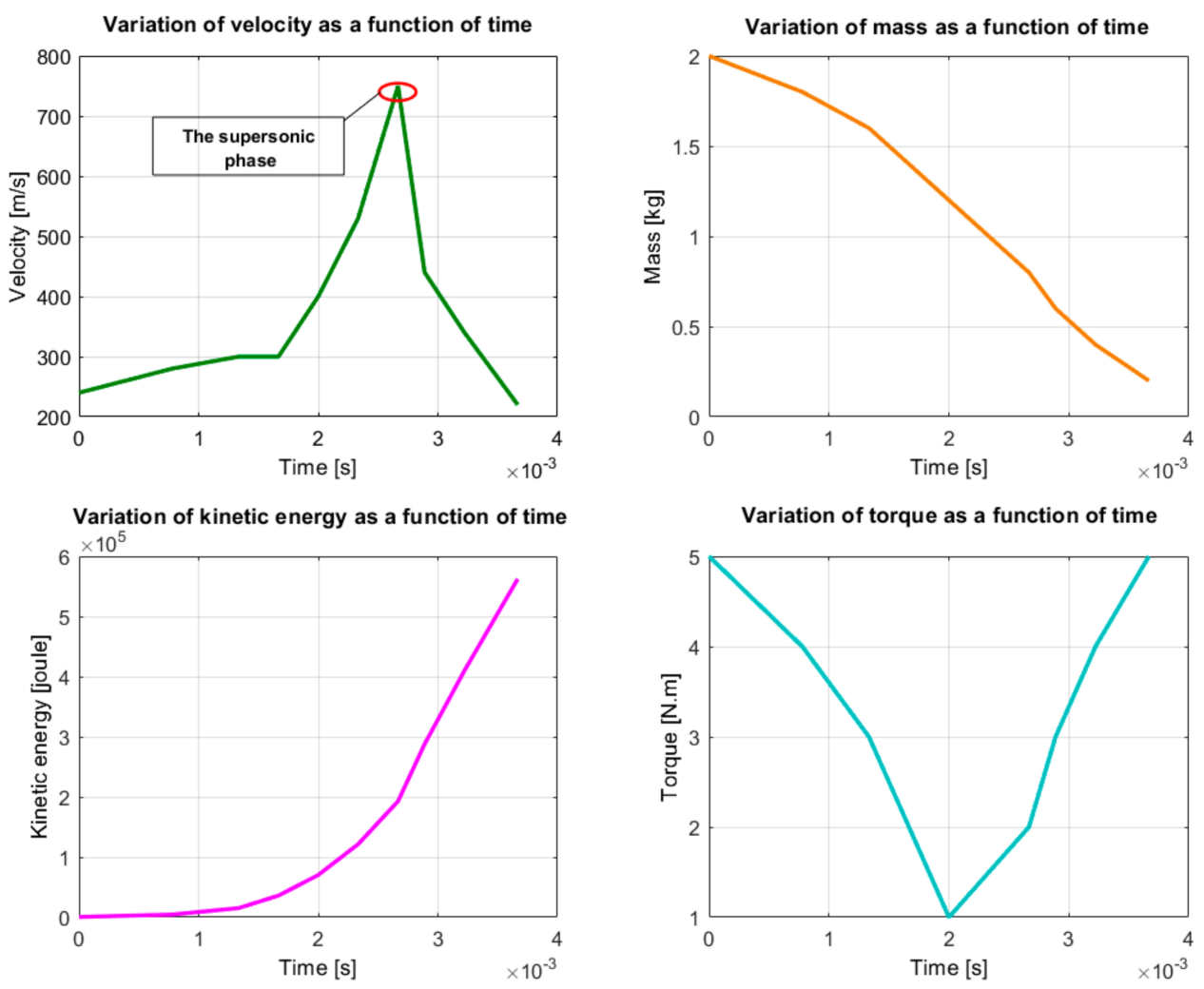

Figure 6. The variation of velocity, mass, kinetic energy, and torque as a function of time.

As we mentioned earlier, the motion of a whip is based on the momentum conservation from the beginning of the whip to the arrival to the tip, where-before cracking-many parameters vary, such as the moving mass along the whip which will be decreased and produce high velocity, presenting the supersonic boom. This phenomenon results in diminution in the torque and an increase in kinetic energy, as Figure 5 shows. A similar effect of conserving momentum can be seen in case of a figure skater doing a spin, when the skater closes his/her hands to his/her body, thus decreasing the rotational inertia and increasing the rotational velocity. Borrowing this characteristic of the motion from whip and considering the robot arm as a similar shape, the increase in the velocity of the robot parts will decrease the cycle time, so the motion of the robot arm can be used like in the mentioned whip or 
skater examples. The whip analogue fits the robot arm better because the arm is similar to a whip. It has many conjoined arm elements that become slimmer from the basement to the gripper.

\subsection{Modelling of RV-2AJ Arm Motion as Whip-Lashing in MATLAB Software}

Based on the brief analysis on the motion of the whip and considering the structural similarity to the manipulator arm, the suggestion of a whip-analogous motion and the resulted in trajectory of the gripper seems to be rational. In this article, we applied the same principle to the RV-2AJ arm, where the robot acted as a whip and the gripper executed the trajectory between two points faster than it otherwise would. The whip-lashing motion of the robot arm can be followed through the sub-figures of Figure 7. When the second joint rotation stopped, the momentum WAS transferred to the third and fourth joints. As the moving mass became smaller, the rotational velocity increased at the last links of the robot arm.

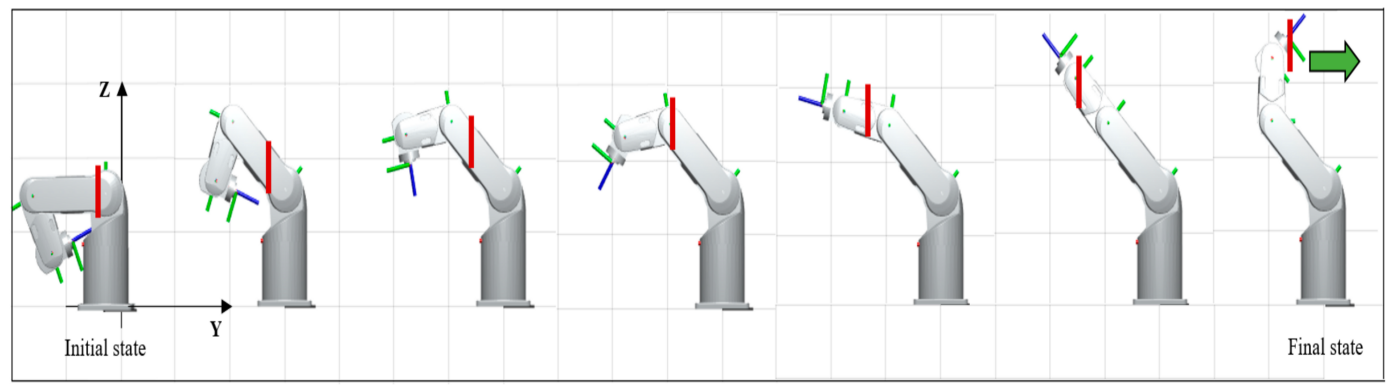

Figure 7. The motion of RV-2AJ arm.

The first step of operation of RV-2AJ arm started with the heavier segment, where the movement was realized by the torque applied at the second joint, at the "closer part to the base". In addition, the rotational inertia decreased when the motion of the links reached the smallest segment "end effector". As the motion proceeded the speedy "closer part to the base" decelerated and the outer joints opened. Finally, the "closer part to the base" stopped and the other joints finish the motion speeding up the motion of the "end effector".

In order to prove the efficiency of whip-lashing method, an iterative algorithm was created to execute the two trajectories (original and improved, see Sections 2.2 and 2.3) and calculated the minimal cycle time of each, trying to apply the maximum allowed torques for the joints.

The core of the algorithm inputted a given larger expected cycle time and determined the joint torque functions along the trajectory. If no torque maximum reaches the allowed torque limit for the given joint, the expected cycle time was decreased by a time step and the core process was repeated. If the expected cycle time was too small and the robot could only execute the trajectory with one or more joint torques exceeding the torque limit, then the decreasing time step was halved and the process applied a back step. This was repeated with a smaller time decrease. At the end of this successive approximation, the minimum cycle time that utilized the torque limit-usually this happens for one joint only-was obtained.

\subsection{Elaboration of the Cycle Time Minimization (CTM) Algorithm}

The organigram presented in Figure 8 contains different blocs (A-E) that define the following calculations:

- A: Filling up the TM torques matrix with the $\mathbf{T}$ torque vectors for every $i$-th trajectory point.

- $\quad$ B: Copying the $i$-th $\mathbf{T}$ torque vector in the $i$-th column of the $\mathbf{T M}$ torques matrix.

- C: Determining the $\mathbf{m T}[j]$ maximum torque for the $j$-th joint.

- D: Checking if any joint torque maximum $\mathbf{m T}[j]$ exceeds the allowed torque aT[ $j]$ for the j-th joint.

- $\quad$ E: Refinement of time step ts if necessary and continuing iteration, or finishing if time step ts goes below ending time step ets. 

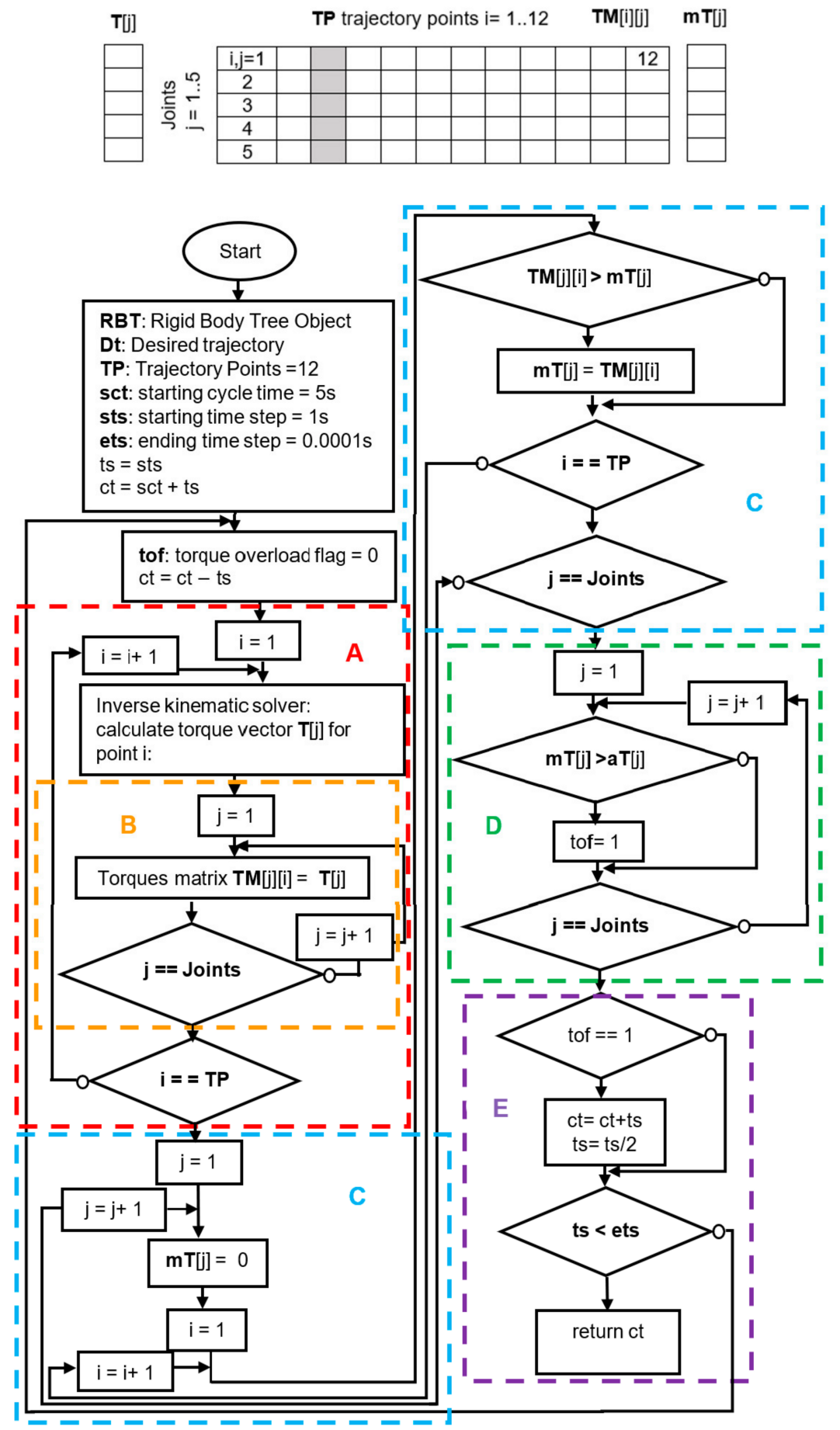

Figure 8. Cycle time minimization algorithm. A-E stand for different blocs that define different calculations.

By running the algorithm for the original and improved trajectories, the two minimum cycle times were determined and compared. In Figure 8, the elaborated cycle time minimization algorithm is introduced in detail.

The algorithm aimed to calculate the cycle time $c t$ of the trajectory. It was made using a successive approximation algorithm as mentioned before. The concrete parameters of the algorithm are the next. The number of trajectory points $T P=12$, where the index of a specified point is $i=1, \ldots, 12$. The number of RV-2AJ arm joints is 5 , where the index of a specified joint is $j=1, \ldots, 5$. In the algorithm two conditions should be fulfilled: 
- $\quad t s \leq e t s$ (ts-time step; ets-ending time step),

- $\mathbf{m T}[j] \leq \mathbf{a T}[j]$ (mT $[j]$ —the joints' torque maximums; $\mathbf{a T}[j]$ —allowed torque for every $j$-th joint).

The algorithm aimed to determine the following data:

The $\mathbf{T}[j]$ torque vector is calculated for every $i$-th trajectory point and copied into the $\mathbf{T M}[j][i]$ torque matrix into the $i$-th column.

The $\mathbf{T}$ torque vector is determined by the "inverse Dynamics MATLAB Robotics System Toolbox function" of the MATLAB Robotic Toolbox. Then, the maximum of every $j$-th row of TM torque matrix is determined to the $j$-th cell of the $\mathbf{m T}[j]$ maximum torque vector. Then the $\mathbf{m T}[j] \leq \mathbf{a T}[j]$ condition setting the tof torque overload flag selects between cycle time decreasing or time step refinement and back stepping.

\section{Discussion: Trajectory Optimization's Results of RV-2AJ Arm Using the Application of CTM Algorithm}

The two trajectories are defined by positioning the same starting and ending points and 10 desired inner points that differ for each path using the spline function of MATLAB script to define the continuous path between the points. Figures 9-12 visualize the code script results for both trajectories (the original and the improved). The static Figures 10 and 12 cannot make the motion of the robot arms felt.

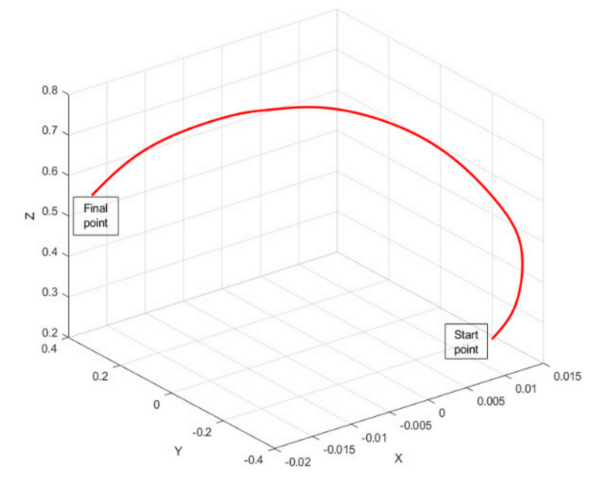

Figure 9. Original trajectory visualization.

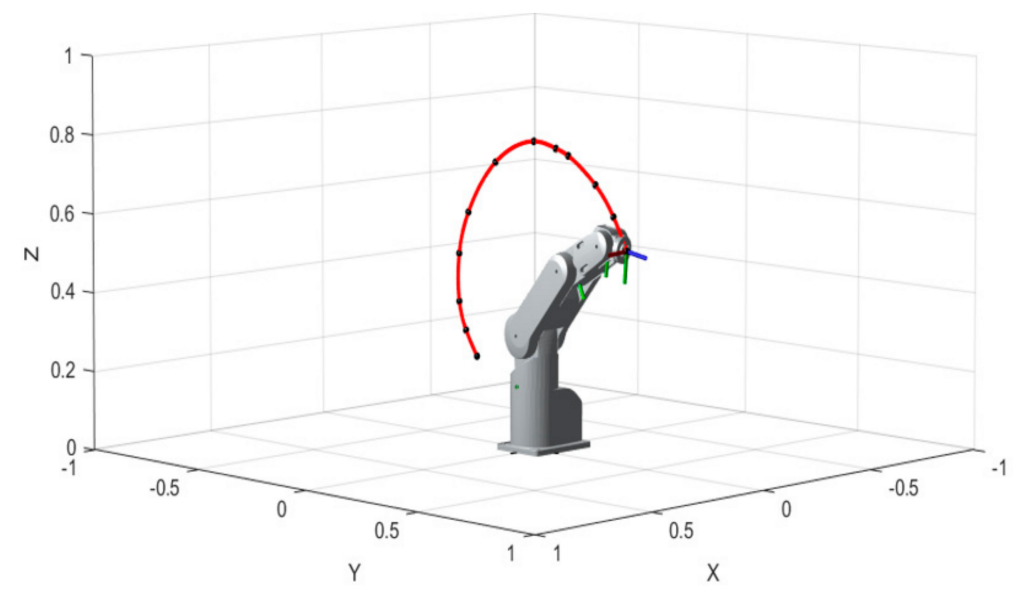

Figure 10. Visualization of the execution of the original trajectory by the RV-2AJ arm. 


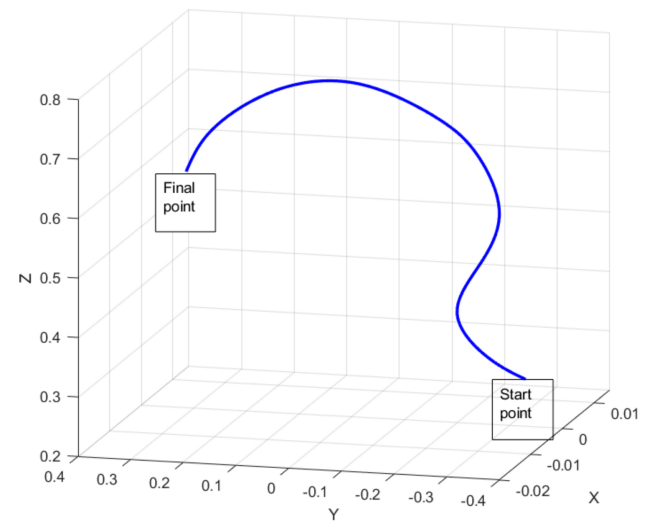

Figure 11. Improved trajectory visualization.

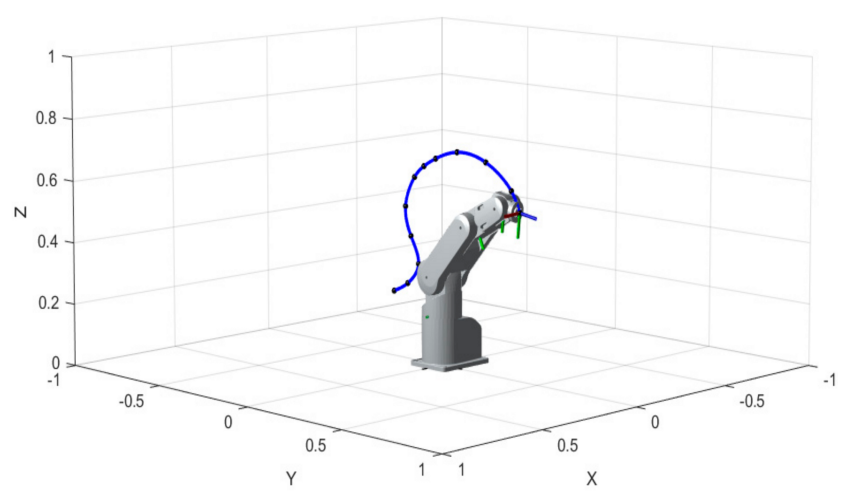

Figure 12. Visualization of the execution of the improved trajectory by RV-2AJ arm.

The execution of script code for both trajectories resulted in the value of cycle time $c t$ for each path, as presented in Figure 13, uniting the two results with drawing manipulation to make comparable the relation between the two trajectories and robot arm motions alike. First, a starting large cycle time $c t=5[\mathrm{~s}]$ was entered as input, then the algorithm was run till we obtained a new cycle time described as the searched cycle time sct when the torque limiting condition became unsatisfied, the algorithm continued to iterate the new values for cycle time $c t$ and time step ts around the searched cycle time value till the value of tuned time step became smaller than the value of ending time step ets. For the original path, the minimum cycle time was $c t=2.82$ [s], while for the improved path, the minimum cycle time was $c t=1.86$ [s]. Comparing the two results, we proved that the improved trajectory, which is described as a whip motion analogue, utilized the maximum allowed torques with shorter cycle time than the original trajectory.

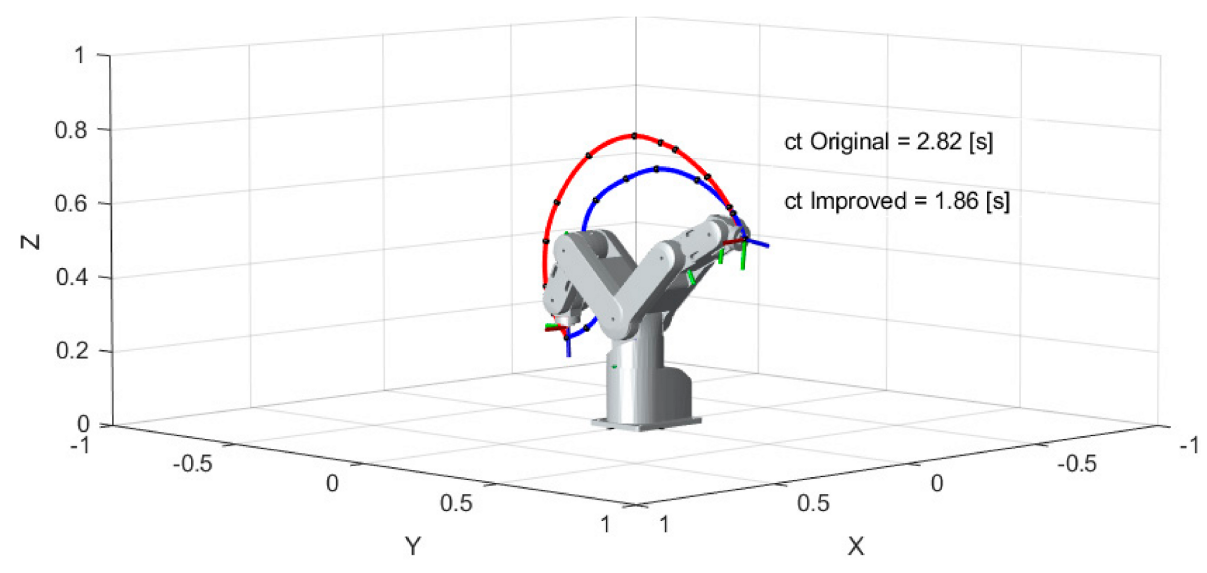

Figure 13. The original and the improved scenarios of RV-2AJ robot arm. 
Modelling of RV-2AJ Arm Motion as Whip-Lashing in MATLAB Software

After studying the cycle time variation, the analysis of torque change effect regarding the both trajectories are discussed in this section. To perform the simulation in the Simulink environment, we imported the RV-2AJ body structure XML file into MATLAB. Then, we configured each link and joint in the structure to receive the vector of positions as input blocks that represent the original and the improved path, as well as to calculate the torques applied for providing the series of such positions.

Figures 14 and 15 present the block system needed to determine the finishing cycle time $c t$ and torque vectors $\mathbf{T}$ calculated during the $c t$ minimizing process, where the blocks "Improved Trajectory" and "Original Trajectory" contain spline function for each joint specified by angles vector that should $\mathrm{RV}-2 \mathrm{AJ}$ arm execute according to each position. "RV-2AJ arm block" contains the mechanical properties of the robot arm.

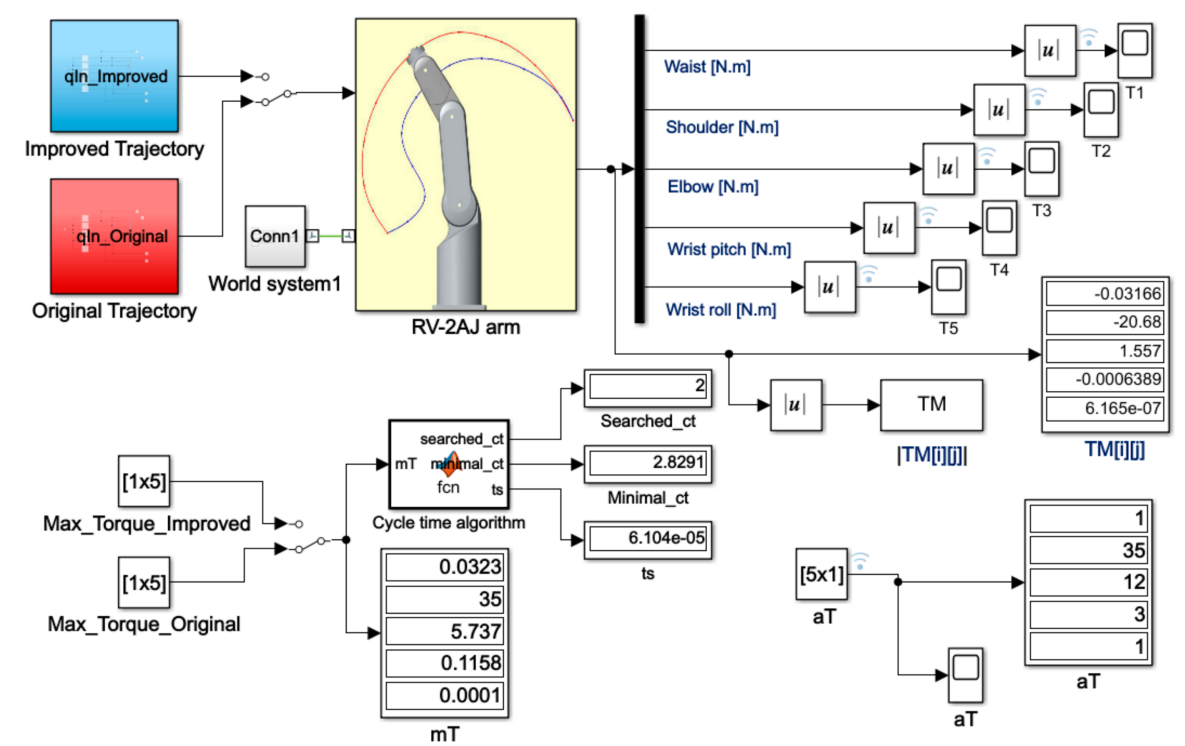

Figure 14. The block system scheme of RV-2AJ arm of the original trajectory.

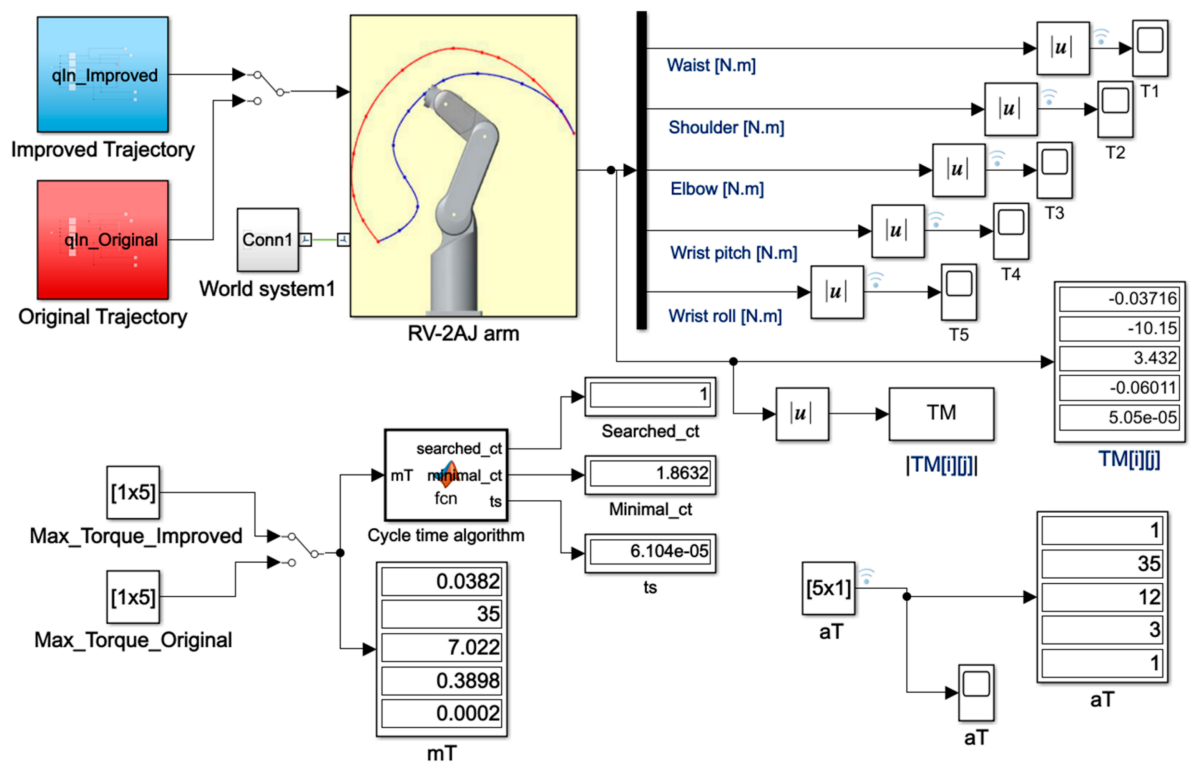

Figure 15. The block system scheme of RV-2AJ arm of the improved trajectory.

Using Scope Box, we visualized the torque diagram of each working joint (second-third-fourth, $j=2,3,4)$ for the original and improved paths (Figure 16). 
In this section, we investigated the variation effect of the second joint (shoulder) and third joint (elbow) regarding the allowable torque values aT for those joints. As can be observed in Figure 16, the variation of torque values for the two paths for a starting cycle time $c t=5[\mathrm{~s}]$ and $t s=1$ [s] describes the behavior of the RV-2AJ arm.

In Figure 16, it can be seen that the torques of the fourth joint are close to zero due to the weight in this segment, which is very small compared to the other segments, which hold other segments. The comparison between the two paths was based on shoulder, which presents the second joint. It was clear that in the first iteration where $c t=5[\mathrm{~s}]$, the torque curve for the original path reached higher peak values than the improved path, where the maximum torque value for the original path was $\mathbf{m T}=31 \mathrm{Nm}$ and for the improved path was $\mathbf{m T}=27 \mathrm{Nm}$. We also observed an overshoot in the beginning stage for both curves, which is explained as the gravity effect on the mechanical structure.

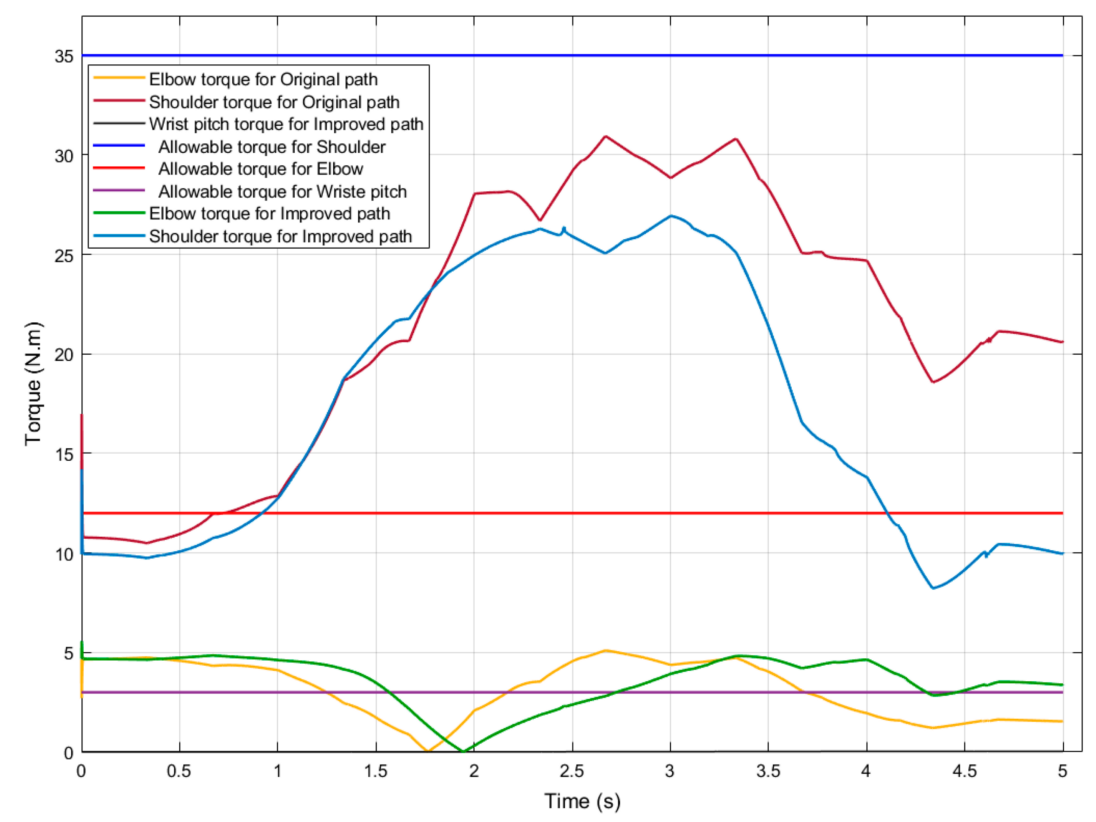

Figure 16. Variation of joint torques according to the two paths, $c t=5[\mathrm{~s}]$.

As mentioned before, we started within a large cycle time $c t=5[\mathrm{~s}]$ and within $t s=1$ as a first iteration. The algorithm of minimization of cycle time started to calculate maximum torque for such a cycle time. If the maximum torque was always below the allowable torque for every joint, then the cycle time $c t$ decreased by the time step ts.

Figure 17 presents the variation of joints torques according to the original path for different cycle times $c t=5,4,3,2$ [s] to see the behavior of torque curves and compare their peak values in each iteration, in order to observe when the torque peak of an iteration exceeds the allowable torque value aT.

Regarding the second joint (shoulder), in the interval 0-5 [s] we observed that the decrease of cycle time resulted in an increase of torque value for the original trajectory, where in $c t=2[\mathrm{~s}]$ the maximum torque value of the original trajectory exceeded the allowable torque value with $\mathbf{m T}=42[\mathrm{~N} \cdot \mathrm{m}]$. Therefore, this value $c t=2[\mathrm{~s}$ ] was stored as the searched cycle time value $s c t$ for the original trajectory and according to this value we calculated a new time step which was smaller than the first one, so the algorithm iterated the cycle time value more precisely. 


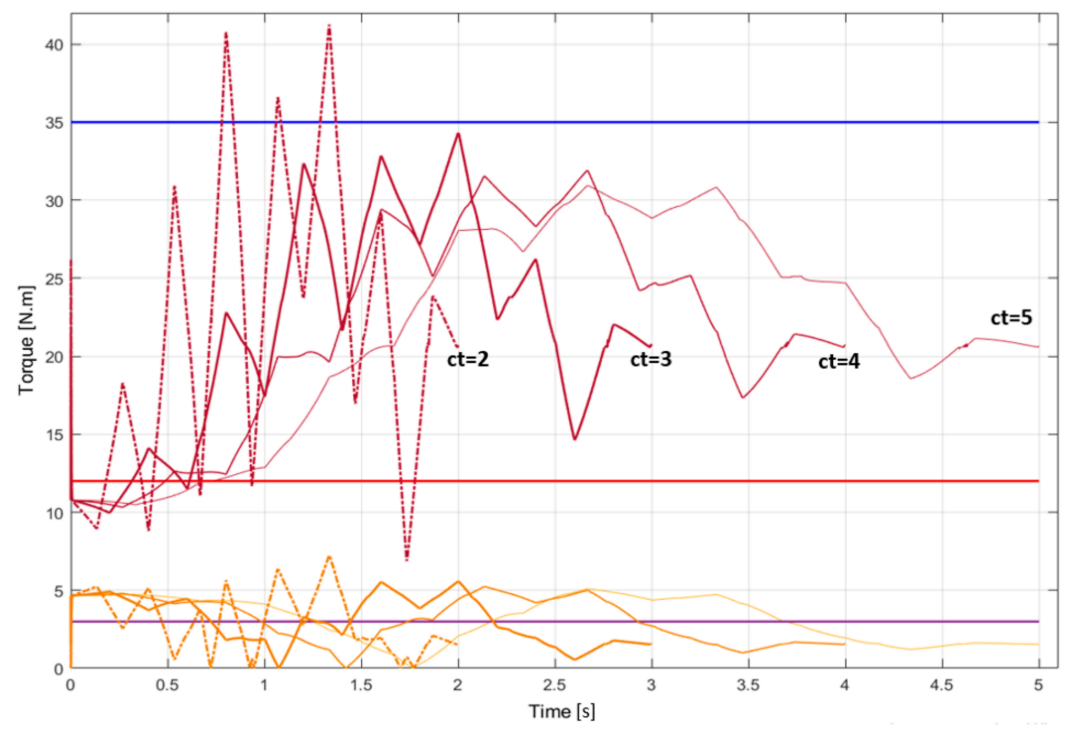

Figure 17. Variation of joint torques—original path—for different cycles.

As presented in Figure 18, the searched cycle time $s c t=2[\mathrm{~s}]$ obtained for the original path minimized the possible range to find the optimal maximum torque with optimal new cycle time. As a result, the optimal curve for shoulder was the red curve with $c t=2.82$ [s]; this curve was obtained after the necessary iterations, starting from the first one, then minimizing the torque till obtaining the optimal curve, the "fourth iteration" $\mathrm{m}$ and because we had a condition to stop iteration when the time step ts was smaller than the ending time step ets; therefore, the algorithm completed the execution and found a better solution with $c t=2.82[\mathrm{~s}]$, as presented in the first section.

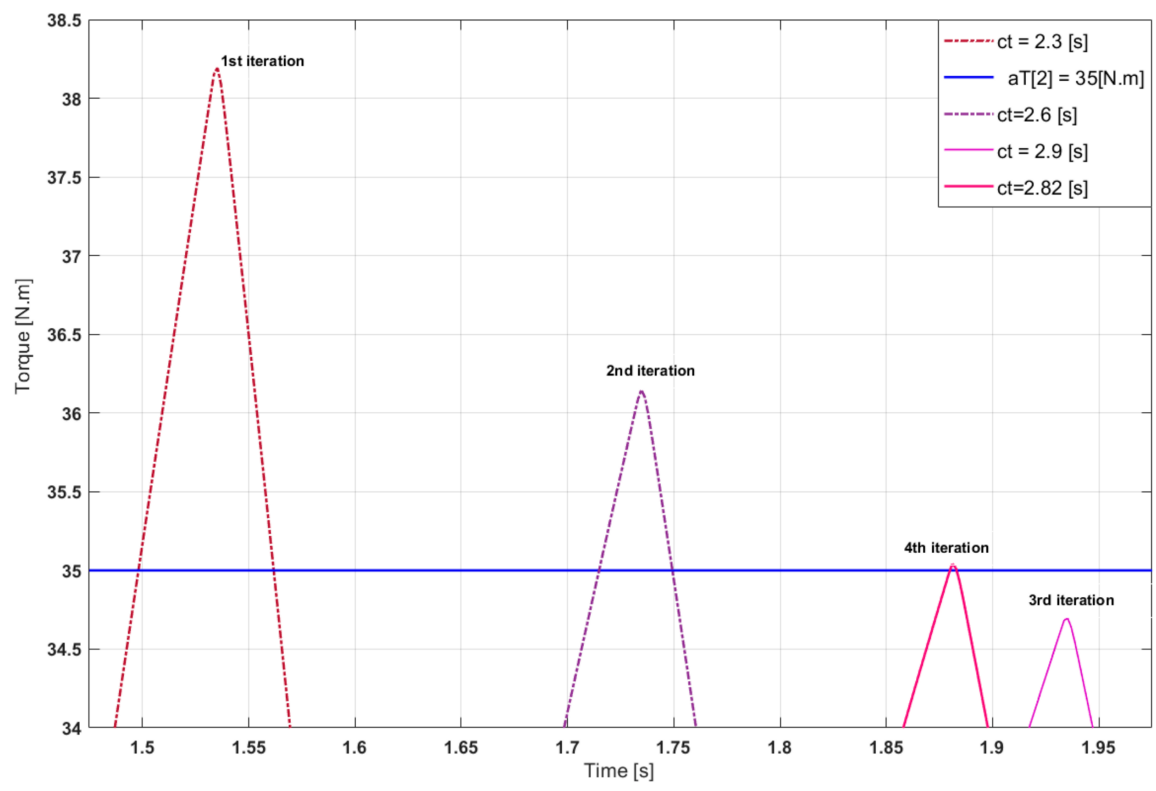

Figure 18. Different iterations of cycle time minimization algorithm for the original path around the searched cycle time $s c t=2[\mathrm{~s}]$.

Figure 19 presents the variation of joint torques for the improved path for different cycle times $c t=5,4,3,2,1$ [s] by executing different iterations of cycle times $c t$ in order to observe when the torque peak of an iteration exceeded the allowable torque value aT. For the improved path at $c t=1$ [s], the maximum torque $\mathbf{m T}=58[\mathrm{~N} \cdot \mathrm{m}]$ exceeded the allowable torque value aT. Therefore, the searched cycle time for the improved path was sct $=1[\mathrm{~s}]$. 


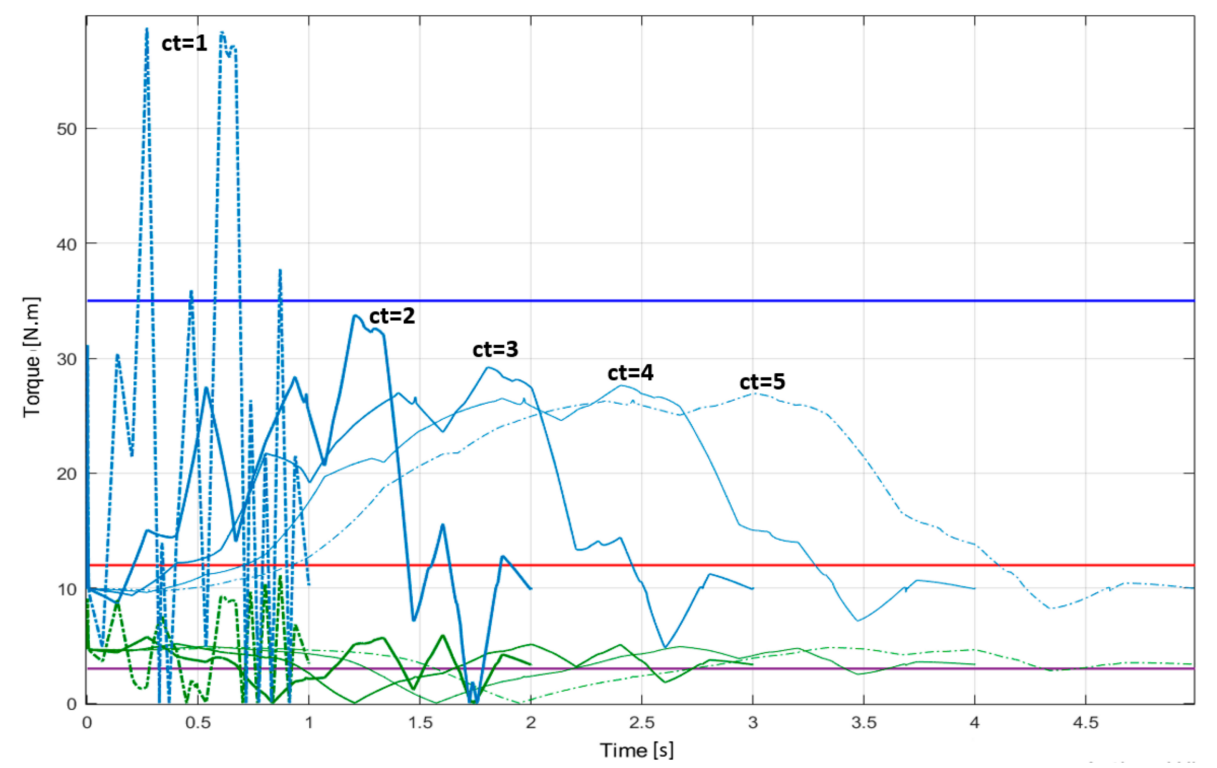

Figure 19. Variation of joints torques according to Improved path for different cycle times $c t=5,4,3,2,1$ [s].

Figure 20 shows the execution of different iterations around the searched cycle time value obtained $s c t=1[\mathrm{~s}]$ from the results of Figure 19 to find the optimal curve. From the diagram, after 4 iterations around the searched cycle time sct $=1[\mathrm{~s}]$, the algorithm achieved the optimal curve with $c t=1.86$ [s]

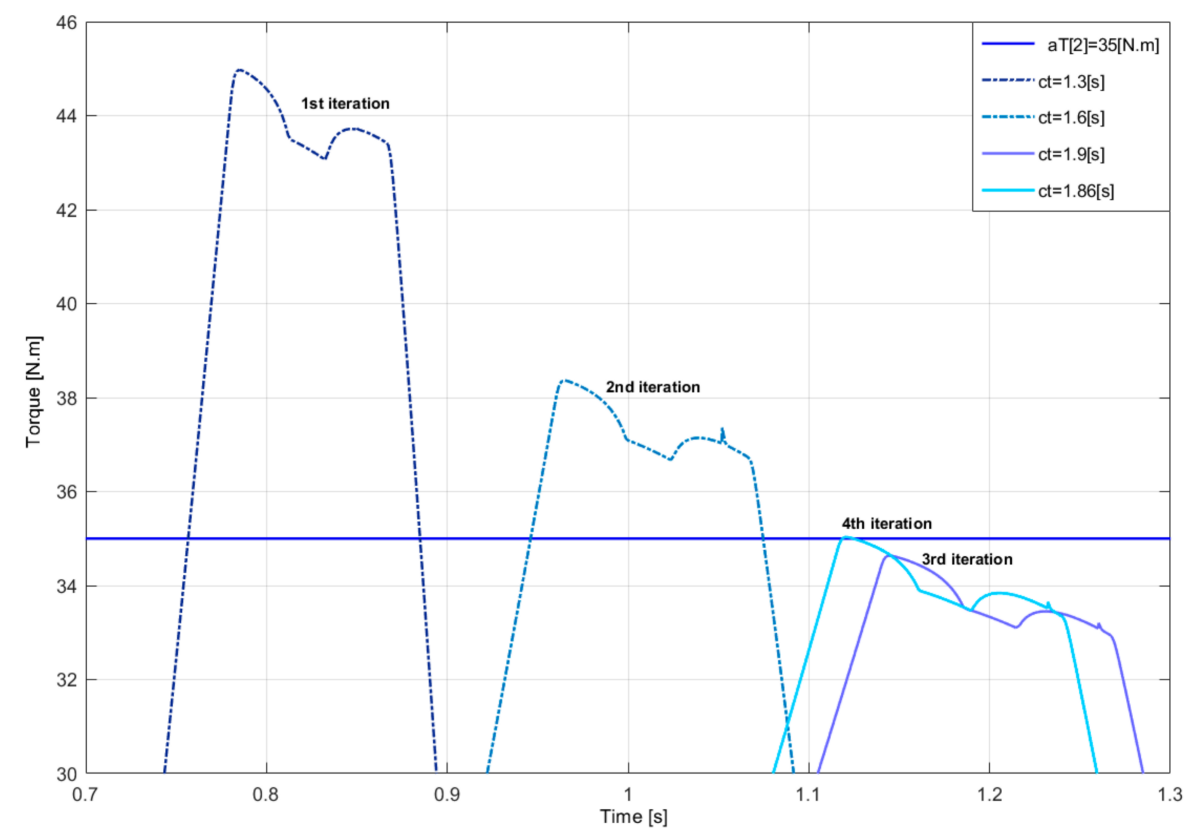

Figure 20. Different iterations of the cycle time minimization algorithm for improved path around the searched cycle time $s c t=1[\mathrm{~s}]$.

Based on the demonstration of diagrams and the comparison between the multi graphs of each path for the second joint, it was clear that the original path exceeded the allowable torque aT optimally with $c t=2.82$ [s], unlike the improved path, which exceeded optimally aT with $c t=1.86$ [s], as presented in Figure 21. Consequently, we proved that the improved path consumed $33 \%$ less time than the original path, which verified the concept of optimization. 


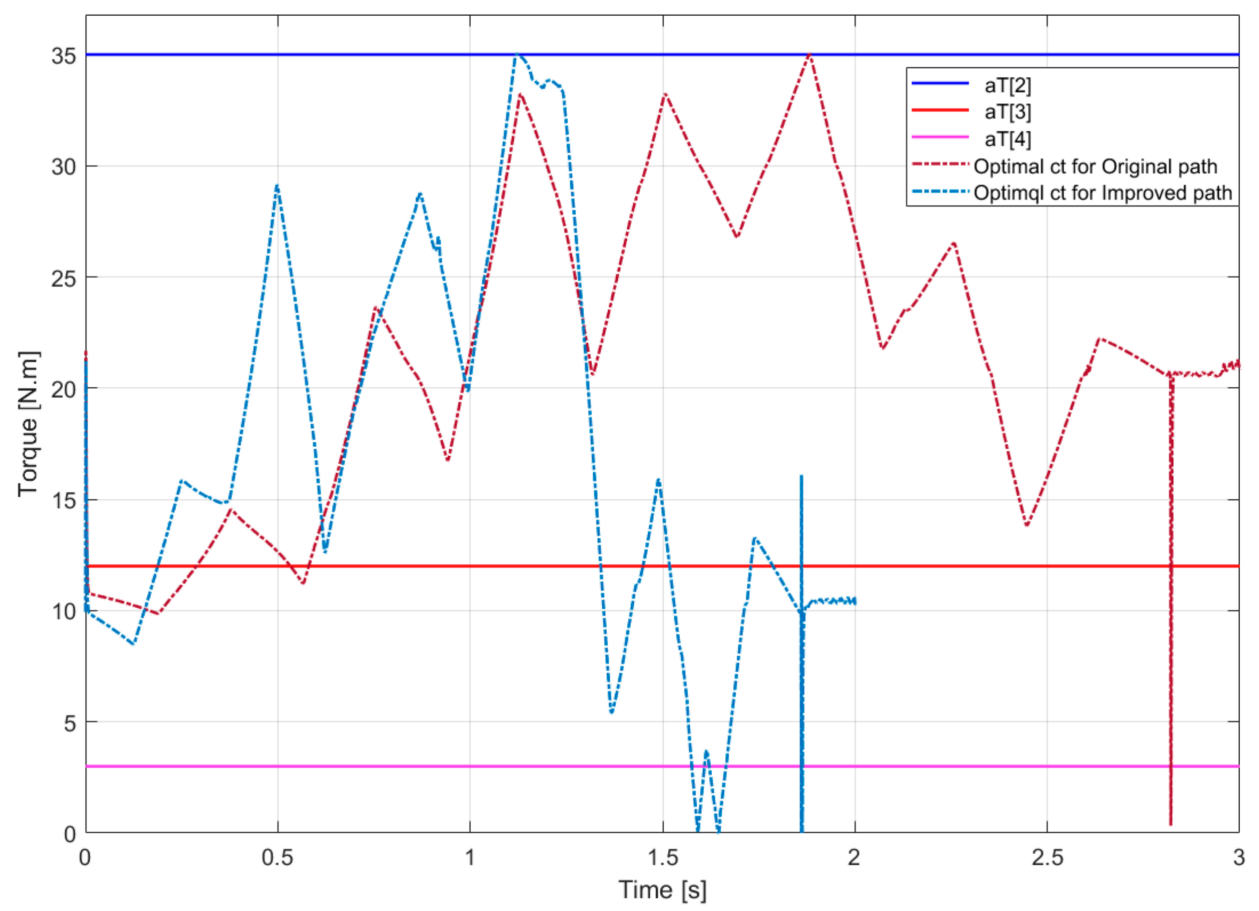

Figure 21. Optimal cycle time values for the original and improved paths.

\section{Conclusions}

The trajectory improvement of industrial robot arms plays an important role in the Industry 4.0 concept, since the trajectory optimization of robot arms reduces cycle times and energy consumption; furthermore, it increases productivity.

At first, a newly elaborated "whip-lashing" method was introduced for the trajectory planning of a robot arm. The idea of the "whip-lashing" method is that the motion and the shape of a whip are similar to the motion and shape of a robot arm, and it results in increasing the velocity of the robot arm's parts during operation; therefore, it reduces the cycle time. With the "whip-lashing" method, the optimized trajectory of the robot arm can be achieved in order to minimize the cycle times of manipulator arms' motion and utilize the torque of joints more effectively.

In the second part of the article, a case study was introduced to confirm the efficiency of the practical applicability of the "whip-lashing" method. In order to realize the idea of the "whip-lashing" method and check its real effect on the cycle time of robot arm motion, SolidWorks and MATLAB software applications were used in the dynamic motion simulations.

In the case study, the trajectory planning of a five-degrees-of-freedom RV-2AJ manipulator arm was described using SolidWorks and MATLAB software applications. At first, the RV-2AJ robot was modelled by the application of SolidWorks software. Two trajectories of the investigated manipulator arm were created using the application of MATLAB software and via the newly elaborated cycle time minimization algorithm. This was done in order to compare the original and the improved paths. It was found that application of the cycle time minimization algorithm resulted in a $33 \%$ shorter cycle time compared to the original path of RV-2AJ robot arm.

The main added value of the study is the elaboration and implementation of the newly elaborated "whip-lashing" method, which resulted in reduction of cycle times of manipulator arms' motion, thus increasing productivity significantly. The efficiency of the new "whip-lashing" method was confirmed by a simulation case study.

The application of this newly elaborated method can provide many advantages in industrial applications in the immediate future, where the robot arms will be designed as the shape of a whip; furthermore, the robot arms will be manufactured by usage of lightweight materials instead of recently used traditional metals. These innovative solutions (application of "whip-lashing" method and 
lightweight materials) will result in more flexible robot arms that can achieve motion with higher speeds without consuming higher energy, by the application of the momentum conservation law. This law can also be used by the existing rotation joint of robot arms where the motion can be achieved in a plain to increase the speed of the robot arm and decrease the motion time. This conception requires the application of new robot controllers and robot simulation software. It can be concluded that the application of the newly elaborated "whip-lashing" method results in achieving the optimized trajectory of the robot arms in order to increase velocity of the robot arm's parts, thereby minimizing motion cycle times and to utilize the torque of the joints more effectively. Consequently, the productivity will be increased significantly.

In the following research, the aim was to find a quasi-optimal trajectory between two given points. The searching for the quasi-optimum solution used the Tabu search method.

Author Contributions: Conceptualization, R.B., L.D., and G.K.; literature review and data collection, R.B.; methodology and software, R.B. and L.D.; formal analysis, R.B., L.D., and G.K.; writing-original draft preparation, R.B.; writing-review and editing, R.B., L.D., and G.K.; visualization, R.B.; supervision, L.D. and G.K.; project administration, L.D. and G.K. All authors have read and agreed to the published version of the manuscript.

Funding: This research and the APC were funded by the Stipendium Hungaricum Scholarship Program launched in 2013 by the Hungarian Government based on bilateral educational cooperation agreements signed between the Ministries responsible for education in the sending countries and Hungary.

Conflicts of Interest: The authors declare no conflict of interest.

\section{References}

1. Benotsmane, R.; Dudás, L.; Kovács, G. Collaborating robots in Industry 4.0 conception. In Proceedings of the XXIII International Conference on Manufacturing, IOP Conference Series: Materials Science and Engineering, Kecskemét, Hungary, 7-8 June 2018; pp. 1-9.

2. Benotsmane, R.; Dudás, L.; Kovács, G. Survey on new trends of robotic tools in the automotive industry. In Vehicle and Automotive Engineering 3; VAE 2020. Lecture Notes in Mechanical Engineering; Springer: Singapore, 2021; pp. 443-457.

3. Dima, I.C.; Kot, S. Capacity of production. In Industrial Production Management in Flexible Manufacturing Systems, 1st ed.; Dima, I.C., Ed.; Book News Inc.: Portland, OR, USA, 2013; pp. 40-67.

4. Kovács, G. Combination of Lean value-oriented conception and facility layout design for even more significant efficiency improvement and cost reduction. Int. J. Prod. Res. 2020, 58, 2916-2936. [CrossRef]

5. Benotsmane, R.; Kovács, G.; Dudás, L. Economic, social impacts and operation of smart factories in Industry 4.0 focusing on simulation and artificial intelligence of collaborating robots. Soc. Sci. 2019, 8, 143. [CrossRef]

6. Delgado, S.D.R.; Kostal, P.; Cagánová, D.; Cambál, M. On the possibilities of intelligence implementation in manufacturing: The role of simulation. Appl. Mech. Mater. 2013, 309, 96-104. [CrossRef]

7. Yildirim, C.; Sevil Oflaç, B.; Yurt, O. The doer effect of failure and recovery in multi-agent cases: Service supply chain perspective. J. Serv. Theory Pract. 2018, 28, 274-297. [CrossRef]

8. Gilchrist, A. Industry 4.0: The Industrial Internet of Things; Apress: Bangkok, Thailand, 2014; pp. 1-12.

9. El Zoghby, N.; Loscri, V.; Natalizio, E.; Cherfaoui, V. Robot cooperation and swarm intelligence. In Wireless Sensor and Robot Networks: From Topology Control to Communication Aspects, 1st ed.; Mitton, N., Simplot-Ryl, D., Eds.; World Scientific Publishing Company: Lille, France, 2014; pp. 168-201.

10. Alessio, C.; Maratea, M.; Mastrogiovanni, N.; Vallati, M. On the manipulation of articulated objects in human-robot cooperation scenarios. Robot. Auton. Syst. 2018, 109, 139-155.

11. Benotsmane, R.; Dudás, L.; Kovács, G. Trial—and-error optimization method of pick and place task for RV-2AJ robot arm. In Vehicle and Automotive Engineering 3; VAE 2020. Lecture Notes in Mechanical Engineering; Springer: Singapore, 2021; pp. 458-467.

12. Yim, M.; Shen, W.; Salemi, B.; Rus, D.; Moll, M.; Lipson, H.; Klavins, E.; Chirikjian, G.S. Modular self-reconfigurable robot systems. IEEE Robot. Autom. Mag. 2007, 14, 43-52. [CrossRef]

13. Koren, Y.; Heisel, U.; Jovane, F.; Moriwaki, T.; Pritschow, G.; Ulsoy, G.; Van Brussel, H. Reconfigurable manufacturing systems. CIRP Ann. Manuf. Technol. 1999, 48, 527-540. [CrossRef] 
14. Lewis, F.L.; Abdallah, C.T.; Dawson, D.M.; Lewis, F.L. Robot Manipulator Control: Theory and Practice, 2nd ed.; Marcel Dekker: New York, NY, USA, 2004.

15. Wissama, K.; Etienne, D. Modélisation Identification et Commande des Robots, 2nd ed.; Harmes: Lavoisier, France, 1999.

16. Liu, X.; Qiu, C.; Zeng, Q.; Li, A. Kinematics analysis and trajectory planning of collaborative welding robot with multiple manipulators. Procedia CIRP 2019, 81, 1034-1039. [CrossRef]

17. Benotsmane, R.; Kacemi, S.; Benachenhou, M.R. Calculation methodology for trajectory planning of a 6 axis manipulator arm. Ann. Fac. Eng. Hunedoara Int. J. Eng. 2018, 3, 27-32.

18. Coiffet, P. Les robots: Modélisation et Commande, 1st ed.; Hermes Science Publications: Paris, France, 1986.

19. Kim, H.; Hong, J.; Ko, K. Optimal design of industrial manipulator trajectory for minimal time operation. KSME J. 1990, 4. [CrossRef]

20. Straka, M.; Žatkovič, E.; Schréter, R. Simulation as a means of activity streamlining of continuously and discrete production in specific enterprise. Acta Logist. 2014, 1, 11-16. [CrossRef]

21. Doan, Q.V.; Vo, A.T.; Le, T.D.; Kang, H.-J.; Nguyen, N.H.A. A novel fast terminal sliding mode tracking control methodology for robot manipulators. Appl. Sci. 2020, 10, 3010. [CrossRef]

22. Joo, S.-H.; Manzoor, S.; Rocha, Y.G.; Bae, S.-H.; Lee, K.-H.; Kuc, T.-Y.; Kim, M. Autonomous navigation framework for intelligent robots based on a semantic environment modeling. Appl. Sci. 2020, 10, 3219. [CrossRef]

23. Kim, J.; Kim, S.-R.; Kim, S.-J.; Kim, D.-H. A practical approach for minimum-time trajectory planning for industrial robots. Ind. Robot Int. J. 2010, 37, 51-61. [CrossRef]

24. Perumaala, S.; Jawahar, N. Synchronized trigonometric S-curve trajectory for jerk-bounded time-optimal pick and place operation. Int. J. Robot. Autom. 2012, 27, 385-395. [CrossRef]

25. Avram, O.; Valente, A. Trajectory planning for reconfigurable industrial robots designed to operate in a high precision manufacturing industry. Procedia CIRP 2016, 57, 461-466. [CrossRef]

26. Macfarlane, S.; Croft, E.A. Jerk-bounded manipulator trajectory planning: Design for real-time applications. IEEE Trans. Robot. Autom. 2003, 19, 42-52. [CrossRef]

27. Gasparetto, A.; Lanzutti, A.; Vidoni, R.; Zanotto, V. Experimental validation and comparative analysis of optimal time-jerk algorithms for trajectory planning. Robot. Comput. Integr. Manuf. 2012, 28, 164-181. [CrossRef]

28. Liu, H.; Xiaobo, L.; Wenxiang, W. Time-optimal and jerk-continuous trajectory planning for robot manipulators with kinematic constraints. Robot. Comput. Integr. Manuf. 2013, 29, 309-317. [CrossRef]

29. Martínez, J.R.G.; Reséndiz, J.R.; Prado, M.Á.M.; Miguel, E.E.C. Assessment of jerk performance s-curve and trapezoidal velocity profiles. In Proceedings of the XIII International Engineering Congress, Universidad Autónoma de Queretaro, Santiago de Queretaro, Mexico, 15-19 May 2017; pp. 1-7.

30. Fang, Y.; Hu, J.; Liu, W.; Shaw, Q.; Qi, J.; Peng, Y. Smooth and time-optimal S-curve trajectory planning for automated robots and machines. Mech. Mach. Theory 2019, 137, 127-153. [CrossRef]

31. Zheng, K.; Hu, Y.; Wu, B. Trajectory planning of multi-degree-of-freedom robot with coupling effect. Mech. Sci. Technol. 2019, 33, 413-421. [CrossRef]

32. Gasparetto, A.; Zanotto, V. A new method for smooth trajectory planning of robot manipulators. Mech. Mach. Theory 2007, 42, 455-471. [CrossRef]

33. Xidias, E.K. Time-optimal trajectory planning for hyper-redundant manipulators in 3D workspaces. Robot. Comput. Integr. Manuf. 2018, 50, 286-298. [CrossRef]

34. Hirakawa, A.; Kawamura, A. Trajectory planning of redundant manipulators for minimum energy consumption without matrix inversion. In Proceedings of the International Conference on Robotics and Automation, Albuquerque, NM, USA, 25 April 1997; Volume 3, pp. 2415-2420.

35. Baghli, F.Z.; El Bakkali, L.; Yassine, L. Optimization of arm manipulator trajectory planning in the presence of obstacles by ant colony algorithm. Procedia Eng. 2017, 181, 560-567. [CrossRef]

36. Saramago, S.F.P.; Steffen, V. Optimization of the trajectory planning of robot manipulators taking into account the dynamics of the system. Mech. Mach. Theory 1998, 33, 883-894. [CrossRef]

37. Devendra, G.; Manish, K. Optimization techniques applied to multiple manipulators for path planning and torque minimization. Eng. Appl. Artif. Intell. 2002, 15, 241-252.

38. Zhang, Y.; Shuzhi, S.G.; Tong, H.L. A unified quadratic-programming-based dynamical system approach to joint torque optimization of physically constrained redundant manipulators. IEEE Trans. Syst. 2014, 34, 2126-2132. [CrossRef] 
39. Ding, H.; Li, Y.F.; Tso, S.K. Dynamic optimization of redundant manipulators in worst case using recurrent neural networks. Mech. Mach. Theory 2000, 35, 55-70. [CrossRef]

40. Saxena, P.; Stavropoulos, P.; Kechagias, J.; Salonitis, K. Sustainability assessment for manufacturing operations. Energies 2020, 13, 2730. [CrossRef]

41. Onwubolu, G. A Comprehensive Introduction to SolidWorks; SDC Publications: Mission, KS, USA, 2013.

42. Perutka, K. MATLAB for Engineers-Applications in Control, Electrical Engineering, IT and Robotics; Intech: Rijeka, Croatia, 2011.

43. Corke, P. Robotics, Vision E Control: Fundamental Algorithms in MATLAB, 2nd ed.; Springer: Victoria, Australia, 2017.

44. Goriely, A.; McMillen, T. Shape of a Cracking Whip. Phys. Rev. Lett. 2002, 88, 244301. [CrossRef]

45. Henrot, C. Characterization of Whip Targeting Kinematics in Discrete and Rhythmic Tasks. Bachelor's Thesis, MIT, Cambridge, MA, USA, 23 June 2016.

46. Krehl, P.; Engemann, S.; Schwenkel, D. The puzzle of whip cracking-Uncovered by a correlation of whip-tip kinematics with shock wave emission. Shock Waves 1998, 8, 1-9. [CrossRef]

Publisher's Note: MDPI stays neutral with regard to jurisdictional claims in published maps and institutional affiliations.

(C) 2020 by the authors. Licensee MDPI, Basel, Switzerland. This article is an open access article distributed under the terms and conditions of the Creative Commons Attribution (CC BY) license (http://creativecommons.org/licenses/by/4.0/). 